\title{
Frequency Response Characteristic (FRC) Curve and Fast Frequency Response Assessment in High Renewable Power Systems
}

\author{
Shutang You
}

\begin{abstract}
This letter introduces a frequency response characteristic (FRC) curve and its application in high renewable power systems. In addition, the letter presents a method for fast frequency response assessment and frequency nadir prediction without performing dynamic simulations using detailed models. The proposed FRC curve and fast frequency response assessment method are useful for operators to understand frequency response performance of high renewable systems in real time.
\end{abstract}

Index Terms - Frequency response characteristic (FRC) curve, frequency response, renewable generation, governor.

\section{INTRODUCTION}

Renewable generation is increasing in many power grids [1-6], influencing both operation and planning [7-15]. Since the increase of renewable penetration reduces system inertia and governor response, power system frequency response has become a major concern of high renewable power systems [1630]. The common approach to evaluate system steady-state frequency response is a constant value $\beta$ whose unit is $\mathrm{MW} / 0.1 \mathrm{~Hz}$ [31-35]. This value is often used for frequency response monitoring in wide-area measurement systems (which have many other situational awareness applications [36-57]). It is also referred to as Frequency Response Obligation (FRO). This value gives a power system's real power generation increase per $0.1 \mathrm{~Hz}$ system frequency decrease. However, this constant value cannot depict the non-linearity caused by governor deadbands and generator headroom limits, as well as various emerging frequency-responsive resources [58-60]. Consequently, operators can hardly evaluate the system frequency response capability over a range of frequency deviations.

This letter introduces a power system frequency response characteristic (FRC) curve, as a more comprehensive metric for evaluating the frequency response capability accurately and procuring frequency response sources cost-effectively. In addition, a simplified frequency response model is proposed for fast prediction of frequency nadir, which supports the decision of under-frequency remedy strategies.

\section{FREQUENCY RESPONSE CHARACTERISTIC CURVE AND FAST FREQUENCY RESPONSE ASSESSMENT}

\section{A. Frequency Response Characteristic (FRC) Curve}

The proposed FRC curve is defined as the system steady-state frequency response capability at different frequency deviation

This work was supported by the U.S. Department of Energy SunShot Office SuNLaMP program under award number 30844 and also made use of Engineering Research Center Shared Facilities supported by the Engineering Research Center Program of the National Science Foundation and DOE under

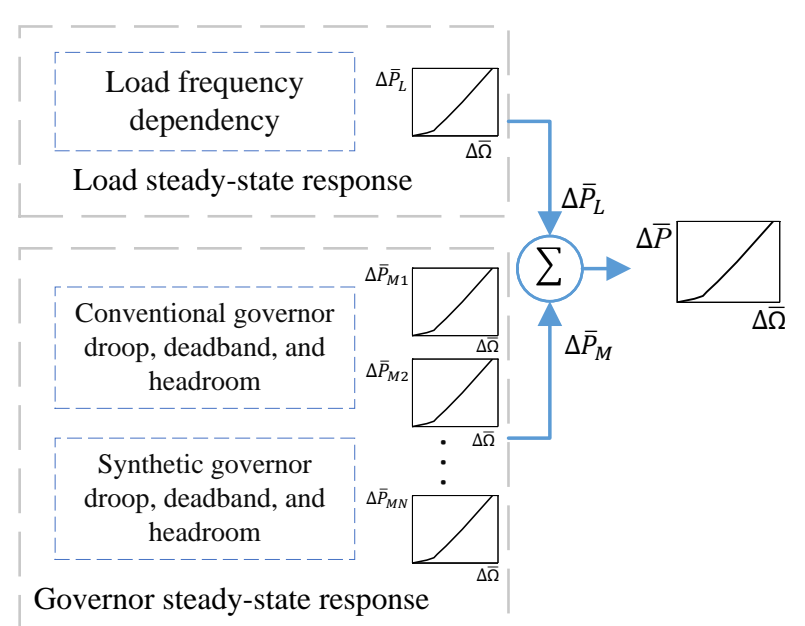

Fig. 1. System frequency response characteristic (FRC) curve generation

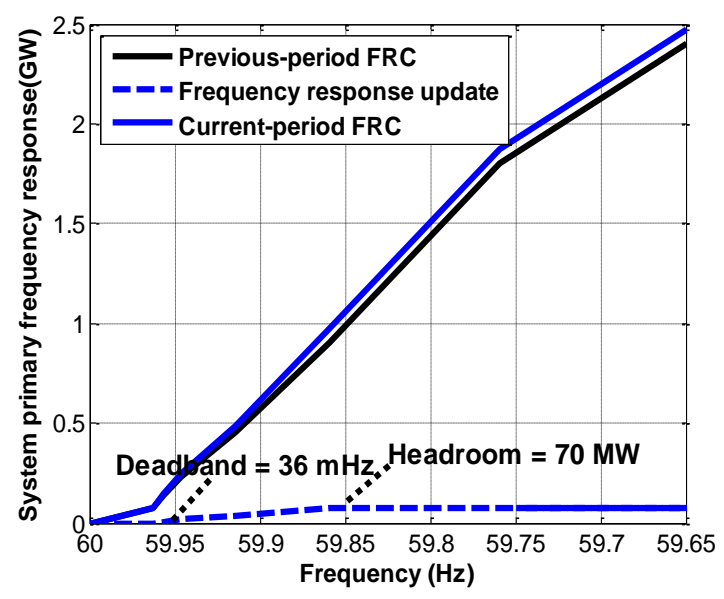

Fig. 2. System FRC curve updates

levels. It is an extension of the commonly used $\beta$ value, which can only represent a linear relation between system response and frequency deviation. Incorporating non-linear characteristics from both governor response and load damping, the FRC curve can help operators easily perceive system frequency response capability after different magnitudes of contingencies and at various frequency deviation levels. The FRC curve can be obtained based on data available in the control centers, including the unit on/off statuses, parameters of governors (such as deadbands, droop ratios, and headroom), and the damping of loads.

NSF Award Number EEC-1041877 and the CURENT Industry Partnership Program.

Shutang You is with the Department of Electrical Engineering and Computer Science, the University of Tennessee, Knoxville, TN 37996 USA (email: syou3@vols.utk.edu) 


$$
F_{F R C}=\sum_{i=1, . . N} x_{i} \cdot f_{i}+f_{L}
$$

where $F_{F R C}$ is the system FRC curve. $x_{i}$ and $f_{i}$ are the on/off status and each unit's FRC curve, respectively. $f_{L}$ is the load damping characteristic. The formulation of the system FRC curve is summarized graphically in Fig. 1. Using the operation plan of each unit, the FRC curve can also be conveniently updated in real time and predicted in short term by superimposing the frequency response characteristic of this unit onto the original FRC curve:

$$
F_{F R C}^{\prime}=F_{F R C}+\sum_{\emptyset} \Delta f_{\varphi}
$$

where $F_{F R C}^{\prime}$ is the FRC curve for previous period; $\Delta f_{\varphi}$ is the frequency response characteristic of newly-turned-on unit $\varphi$. Taking various profiles, $\Delta f_{i}$ can represent any resource that provides frequency response, including synthetic governors from inverters of renewables and energy storage. Fig. 2 shows an example of updating the system FRC curve after turning on a governor-responsive unit with deadband and headroom.

\section{B. Fast Frequency Response Assessment (Frequency Nadir Prediction)}

For power systems with obvious frequency nadir in frequency response, such as the U.S. Electric Reliability Council of Texas system (ERCOT) and Western Electricity Coordinating Council (WECC) systems, fast prediction of frequency nadir is very important for taking remedial measures to prevent underfrequency load shedding during frequency transient periods. As a transient attribute, frequency nadir prediction involves system inertia and dynamics of governors and turbines. The block diagram shown in Fig. 3 is proposed for fast assessment of frequency response and prediction of the frequency nadir. In this approach, the inertia $H$ is estimated based on the current operation plan (on/off status) submitted by each generator [61]. The aggregation of governors and turbine models is performed based on clustering governor/turbine dynamic models and associated parameters, which are largely determined by the technology type and capacities of in-service generators. For 'always-on' units (continuously operating for more than 24

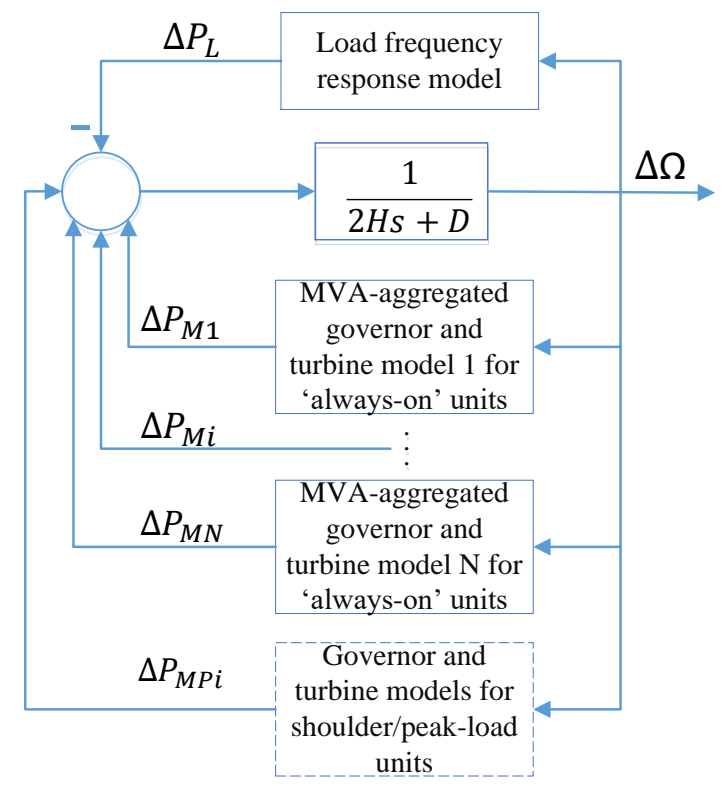

Fig. 3. Fast frequency response assessment (frequency nadir prediction) diagram hours), the clustering and aggregation are performed off line, while shoulder-load and peak-load units are modeled individually for update convenience during operation.

\section{CASE STUDIES}

This case study is based on the detailed models of two interconnections of the U.S.: the Eastern Interconnection system (EI) and the ERCOT. For each system, a series of models representing high renewable scenarios have been developed [15]. The obtained FRC curves of EI in different

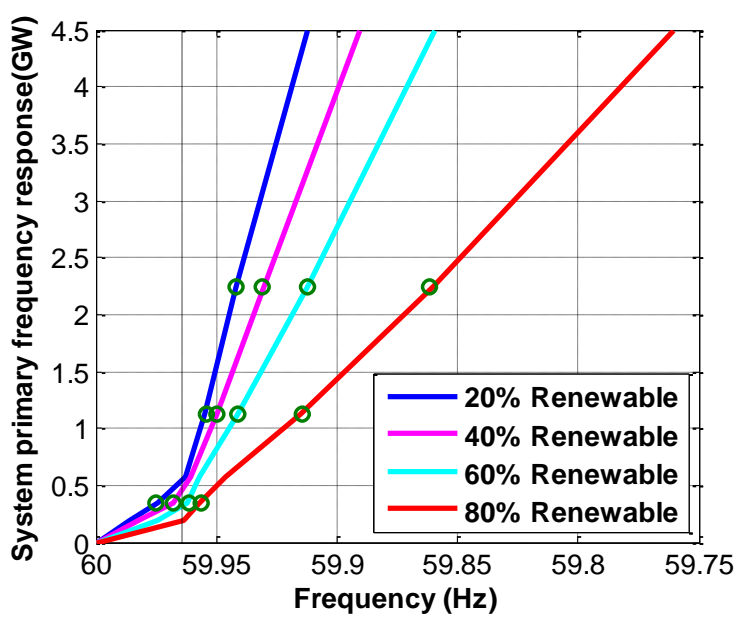

Fig. 4. The EI system FRC curves in various renewable penetration scenarios

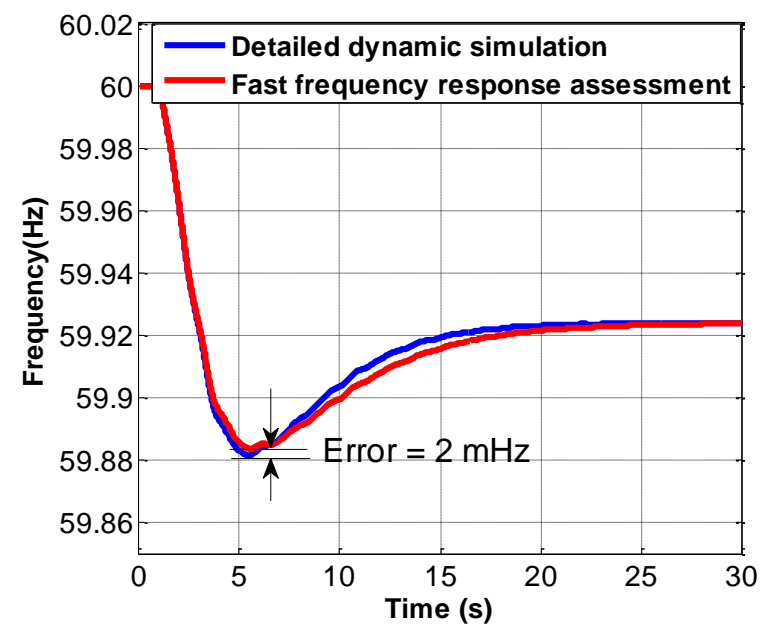

Fig. 5. Fast frequency response assessment (frequency nadir prediction) in ERCOT (200MW loss, $60 \%$ renewable scenario)

renewable penetration scenarios are shown in Fig. 4. In this figure, the turn points of the FRC curves near $59.964 \mathrm{~Hz}$ (the dash line) reflect the effects of governor deadbands on system frequency response $(0.036 \mathrm{~Hz}$ is the common deadband value in the EI system). The green circles represent the EI steady-state frequency obtained using the full dynamic simulation and applying different contingencies. These results show that FRC curve can provide operators an accurate picture of system frequency response capability adequacy at the full frequency band.

With less inertia compared with the EI, the ERCOT shows an obvious nadir in frequency response, which is a focus point of ERCOT operators. Fig. 5 is a comparison of the fast frequency response assessment result and the detailed model 
result of ERCOT. It shows that the proposed model can accurately predict the frequency nadir, alerting the potential need for under-frequency remedial actions. In addition, as a supplementary of the proposed FRC curve, which addresses frequency response capacity adequacy, the proposed model can help operators and planners evaluate the impact of deployment time of frequency response resources, which is critical for lowinertia systems.

\section{CONCLUSIONS}

This letter introduces a frequency response characteristic (FRC) curve and its application in high renewable power systems. In addition, the letter presents a method for fast frequency response assessment and frequency nadir prediction without performing dynamic simulations using detailed models. The effectiveness of the proposed technology in predicting the frequency nadir is verified in the ERCOT study system. The proposed FRC curve and fast frequency response assessment method are useful for operators to understand frequency response performance of high renewable systems in real time.

\section{REFERENCES}

1. Guo, J., et al. An ensemble solar power output forecasting model through statistical learning of historical weather dataset. in 2016 IEEE Power and Energy Society General Meeting (PESGM). 2016. IEEE.

2. Hadley, S., et al., Electric grid expansion planning with high levels of variable generation. ORNL/TM-2015/515, Oak Ridge National Laboratory, 2015.

3. Hadley, S.W. and S. You, Influence Analysis of Wind Power Variation on Generation and Transmission Expansion in US Eastern Interconnection.

4. Sun, K., et al., A Review of Clean Electricity Policies-From Countries to Utilities. Sustainability, 2020. 12(19): p. 7946.

5. You, S., Electromechanical Dynamics of High Photovoltaic Power Grids. 2017.

6. You, S., et al., Co-optimizing generation and transmission expansion with wind power in large-scale power gridsImplementation in the US Eastern Interconnection. Electric Power Systems Research, 2016. 133: p. 209-218.

7. Lv, C., et al., Short - term transmission maintenance scheduling based on the benders decomposition. International Transactions on Electrical Energy Systems, 2015. 25(4): p. 697-712.

8. Till, A., S. You, and Y. Liu, Impact of High PV Penetration on Transient Stability - a Case Study on the US ERCOT System.

9. Wang, J., et al., Long-term maintenance scheduling of smart distribution system through a PSO-TS algorithm. Journal of Applied Mathematics, 2014. 2014.

10. Wang, J., et al., Flexible transmission expansion planning for integrating wind power based on wind power distribution characteristics. J. Electr. Eng. Technol, 2015. 10: p. 709-718.

11. Wang, R., et al. A Novel Transmission Planning Method for Integrating Large-Scale Wind Power. in 2012 Asia-Pacific Power and Energy Engineering Conference. 2012. IEEE.

12. Xiao, H., et al., Data-Driven Security Assessment of Power Grids Based on Machine Learning Approach. 2020, National Renewable Energy Lab.(NREL), Golden, CO (United States).

13. You, S., et al., Oscillation mode identification based on wide-area ambient measurements using multivariate empirical mode decomposition. Electric Power Systems Research, 2016. 134: p. 158-166.

14. You, S., et al. Ring-down oscillation mode identification using multivariate empirical mode decomposition. in 2016 IEEE Power and Energy Society General Meeting (PESGM). 2016. IEEE.

15. You, S., et al., Impact of high PV penetration on the inter-area oscillations in the US eastern interconnection. IEEE Access, 2017. 5: p. 4361-4369.
16. $\quad \mathrm{Li}, \mathrm{H}$., et al., Analytic analysis for dynamic system frequency in power systems under uncertain variability. IEEE Transactions on Power Systems, 2018. 34(2): p. 982-993.

17. You, S., et al., Comparative assessment of tactics to improve primary frequency response without curtailing solar output in high photovoltaic interconnection grids. IEEE Transactions on Sustainable Energy, 2018. 10(2): p. 718-728.

18. Tan, J., et al. Developing High PV Penetration Case for Frequency Response study of U.S. Western Interconnection. in The 9th Annual IEEE Green Technologies Conference. March 2017. Denver, Colorado: IEEE.

19. You, S., et al. Energy Storage for Frequency Control in High Photovoltaic Power Grids. in IEEE EUROCON 2019-18th International Conference on Smart Technologies. 2019. IEEE.

20. Yao, W., et al., A fast load control system based on mobile distribution-level phasor measurement unit. IEEE Transactions on Smart Grid, 2019. 11(1): p. 895-904.

21. Yuan, Z., et al. Frequency control capability of Vsc-Hvdc for large power systems. in 2017 IEEE Power \& Energy Society General Meeting. 2017. IEEE.

22. Liu, Y., et al., Frequency response assessment and enhancement of the US power grids toward extra-high photovoltaic generation penetrations-An industry perspective. IEEE Transactions on Power Systems, 2018. 33(3): p. 3438-3449.

23. Tan, J., et al. Frequency Response Study of US Western Interconnection under Extra-High Photovoltaic Generation Penetrations. in 2018 IEEE Power \& Energy Society General Meeting (PESGM). 2018. IEEE.

24. Sun, K., et al., Frequency secure control strategy for power grid with large-scale wind farms through HVDC links. International Journal of Electrical Power \& Energy Systems, 2020. 117: p. 105706.

25. You, S., et al. Impact of High PV Penetration on U.S. Eastern Interconnection Frequency Response. in Power and Energy Society General Meeting (PESGM), 2017. 2017. IEEE.

26. You, S., et al. Impact of high PV penetration on US eastern interconnection frequency response. in 2017 IEEE Power \& Energy Society General Meeting. 2017. IEEE.

27. Yuan, H., et al. Machine Learning-Based PV Reserve Determination Strategy for Frequency Control on the WECC System. in 2020 IEEE Power \& Energy Society Innovative Smart Grid Technologies Conference (ISGT). 2020. IEEE.

28. You, S., et al., Non-invasive identification of inertia distribution change in high renewable systems using distribution level PMU. IEEE Transactions on Power Systems, 2017. 33(1): p. 1110-1112.

29. Liu, Y., S. You, and Y. Liu, Study of wind and PV frequency control in US power grids-EI and TI case studies. IEEE power and energy technology systems journal, 2017. 4(3): p. 65-73.

30. You, S., et al. US Eastern Interconnection (EI) Electromechanical Wave Propagation and the Impact of High PV Penetration on Its Speed. in 2018 IEEE/PES Transmission and Distribution Conference and Exposition (T\&D). 2018. IEEE.

31. NERC, Standard BAL-003-1 - Frequency Response and Frequency Bias Setting. 2014.

32. Hoffman, S. NERC interconnected operations services policy developments related to frequency control. in IEEE Power Engineering Society. 1999 Winter Meeting (Cat. No. 99CH36233). 1999. IEEE.

33. Pappachen, A. and A.P. Fathima, NERC's control performance standards based load frequency controller for a multi area deregulated power system with ANFIS approach. Ain Shams Engineering Journal, 2018. 9(4): p. 2399-2414.

34. Jaleeli, N. and L.S. VanSlyck, NERC's new control performance standards. IEEE Transactions on Power Systems, 1999. 14(3): p. 1092-1099.

35. Lauby, M., et al. Eastern interconnection frequency response trends. in 2013 IEEE Power \& Energy Society General Meeting. 2013. IEEE.

36. Alharbi, A., S. You, and Y. Liu. Correlation between Generator Trips and Locational Marginal Prices (LMPs). in 2020 17th International Conference on the European Energy Market (EEM). 2020. IEEE.

37. Liu, Y., et al. Recent application examples of FNET/GridEye. in 2018 IEEE 12th International Conference on Compatibility, Power 
38. Tong, N., et al. Dynamic Equivalence of Large-Scale Power Systems Based on Boundary Measurements. in 2020 American Control Conference (ACC). 2020. IEEE.

39. Wang, W., et al. Advanced synchrophasor-based application for potential distributed energy resources management: key technology, challenge and vision. in 2020 IEEE/IAS Industrial and Commercial Power System Asia (I\&CPS Asia). 2020. IEEE.

40. Wu, L., et al. Multiple Linear Regression Based Disturbance Magnitude Estimations for Bulk Power Systems. in 2018 IEEE Power \& Energy Society General Meeting (PESGM). 2018. IEEE.

41. $\mathrm{Wu}, \mathrm{L}$., et al. Statistical analysis of the FNET/grideye-detected inter-area oscillations in Eastern Interconnection (EI). in 2017 IEEE Power \& Energy Society General Meeting. 2017. IEEE.

42. You, S., et al. FNET/GridEye for Future High Renewable Power Grids-Applications Overview. in 2018 IEEE PES Transmission \& Distribution Conference and Exhibition-Latin America (T\&D-LA). 2018. IEEE.

43. You, S., et al. A survey on next-generation power grid data architecture. in 2015 IEEE Power \& Energy Society General Meeting. 2015. IEEE.

44. You, S., et al. Data architecture for the next-generation power grid: Concept, framework, and use case. in 2015 2nd International Conference on Information Science and Control Engineering. 2015. IEEE.

45. Zhang, X., et al. US eastern interconnection (EI) model reductions using a measurement-based approach. in 2018 IEEE/PES Transmission and Distribution Conference and Exposition $(T \& D)$. 2018. IEEE.

46. Zhang, X., et al. Measurement-based power system dynamic model reductions. in 2017 North American Power Symposium (NAPS). 2017. IEEE.

47. Zhao, J., et al. Data quality analysis and solutions for distributionlevel PMUs. in 2019 IEEE Power \& Energy Society General Meeting (PESGM). 2019. IEEE.

48. $\mathrm{Li}$, J., et al., A fast power grid frequency estimation approach using frequency-shift filtering. IEEE Transactions on Power Systems, 2019. 34(3): p. 2461-2464.

49. Liu, S., et al., Model-free Data Authentication for Cyber Security in Power Systems. IEEE Transactions on Smart Grid, 2020.

50. Liu, Y., et al., Recent developments of FNET/GridEye-A situational awareness tool for smart grid. CSEE Journal of Power and Energy Systems, 2016. 2(3): p. 19-27.

51. Liu, Y., S. You, and Y. Liu, Smart transmission \& wide area monitoring system. Communication, Control and Security for the Smart Grid, 2017.

52. Liu, Y., et al., A distribution level wide area monitoring system for the electric power grid-FNET/GridEye. IEEE Access, 2017. 5: p. 2329-2338.

53. Wang, W., et al., Information and Communication Infrastructures in Modern Wide-Area Systems. Wide Area Power Systems Stability, Protection, and Security: p. 71-104.

54. Yao, W., et al., Source location identification of distribution-level electric network frequency signals at multiple geographic scales. IEEE Access, 2017. 5: p. 11166-11175.

55. Yao, W., et al., GPS signal loss in the wide area monitoring system: Prevalence, impact, and solution. Electric Power Systems Research, 2017. 147: p. 254-262.

56. You, S., et al., Disturbance location determination based on electromechanical wave propagation in FNET/GridEye: a distribution-level wide-area measurement system. IET Generation, Transmission \& Distribution, 2017. 11(18): p. 4436-4443.

57. Zhang, Y., et al., Impacts of power grid frequency deviation on time error of synchronous electric clock and worldwide power system practices on time error correction. Energies, 2017. 10(9): p. 1283.

58. Virmani, S. Security impacts of changes in governor response. in IEEE Power Engineering Society. 1999 Winter Meeting (Cat. No. 99CH36233). 1999. IEEE.

59. Mohajeryami, S., et al. Modeling of deadband function of governor model and its effect on frequency Response characteristics. in 2015 North American Power Symposium (NAPS). 2015. IEEE.

60. Miller, N., et al., Eastern frequency response study. 2013, National Renewable Energy Lab.(NREL), Golden, CO (United States).

61. Du, P. and J. Matevosyan, Forecast System Inertia Condition and Its Impact to Integrate More Renewables. IEEE Transactions on Smart Grid, 2017. 